\title{
Muscle pedicle bone flap transplantation for treating femoral neck fracture in adults: a systematic review
}

\author{
Yipeng $\mathrm{Wu}^{\dagger}$, Muguo Song ${ }^{\dagger}$, Guangliang Peng ${ }^{\dagger}$, Yongqing $\mathrm{Xu}^{*}$, Yang Li', Mingjie Wei, Hui Tang, Qian LV, \\ Teng Wang and Xingbo Cai
}

\begin{abstract}
Background: This systematic review was conducted to gather available evidence on the effectiveness of muscle pedicle bone flap transplantation in adult patients with femoral neck fractures.

Methods: Databases such as PubMed, EMBASE, IEEE, Web of Science, and Cochrane library were searched from their dates of inception until March 2021. Two reviewers independently selected the interventional studies on the assessment of the effectiveness of muscle pedicle bone flap transplantation for femoral neck fractures; data extraction and assessment of the methodological quality as per the Institute of Health Economics quality appraisal checklist were also performed by the reviewers. The effectiveness and complication outcomes were assessed by calculating the average rates.

Results: Overall, 20 studies with 1022 patients were included in this review. Notably, the methodologic quality of the included studies was typically poor. The average effective rates were as follows: good, 73.4\%; fair, 15.4\%; and poor, $10.9 \%$. Moreover, the average nonunion rate, average avascular necrosis rate, average collapse rate, and the overall reoperation rate were $9.0 \%, 6.7 \%, 4.7 \%$, and $7.3 \%$, respectively.

Conclusions: This systematic review of heterogeneous studies with varying number of patients and varying surgical techniques indicated that muscle pedicle bone flap transplantation provides promising results with low rates of avascular necrosis and nonunion. Nevertheless, further controlled studies are required to ascertain the effectiveness of muscle pedicle bone flap transplantation in treating femoral neck fracture.
\end{abstract}

Keywords: Muscle pedicle bone flap transplantation, Femoral neck fracture, Systematic review, Perioperative complications

\section{Background}

Hip fracture is associated with limited movement, chronic pain, disability, loss of independence, and decline in the quality of life. Moreover, approximately 20 $30 \%$ of patients with hip fractures die within a year $[1$,

\footnotetext{
*Correspondence: docxuyongqing@sina.com; medic_liyang@163.com

${ }^{\dagger}$ Yipeng Wu, Muguo Song and Guangliang Peng contributed equally to this work.

Institute of Traumatology and Orthopaedics, 920th Hospital of Joint Logistics Support Force, PLA, Kunming, China
}

2]. Notably, femoral neck fracture is the most common type of hip fracture. Femoral neck fracture treatment is typically classified into conservative and surgical treatments. Nevertheless, because conservative treatment requires long-term bedrest, the incidence of complications such as pulmonary infection and thrombosis is high. Therefore, most clinicians recommend surgical treatment as the first-line of treatment in old patients with femoral neck fracture [3]. Surgical treatment of displaced intracapsular neck fractures in patients aged more than

(c) The Author(s). 2021 Open Access This article is licensed under a Creative Commons Attribution 4.0 International License, which permits use, sharing, adaptation, distribution and reproduction in any medium or format, as long as you give appropriate credit to the original author(s) and the source, provide a link to the Creative Commons licence, and indicate if changes were made. The images or other third party material in this article are included in the article's Creative Commons licence, unless indicated otherwise in a credit line to the material. If material is not included in the article's Creative Commons licence and your intended use is not permitted by statutory regulation or exceeds the permitted use, you will need to obtain permission directly from the copyright holder. To view a copy of this licence, visit http://creativecommons.org/licenses/by/4.0/ The Creative Commons Public Domain Dedication waiver (http://creativecommons.org/publicdomain/zero/1.0/) applies to the data made available in this article, unless otherwise stated in a credit line to the data. 
70 years entails hip replacement with a partial or total prosthesis - a modality accepted by a vast majority of researchers worldwide. Nonetheless, the conservative treatment is typically recommended in younger patients (<60 years). Moreover, complications such as fracture nonunion and osteonecrosis of the femoral head can easily occur after the femoral neck fracture [4]. The current, tried, and tested surgical treatment methods for ununited femoral neck fractures are internal fixation, internal fixation plus osteotomy with or without bone graft, non-vascularized or vascularized bone graft, and hip arthroplasty [5]. Nevertheless, in developing countries, various factors such as illiteracy, low socioeconomic status, ignorance, and poor medical facilities might cause a delay in surgical treatment. Squatting and sitting cross-legged are inherently involved in the activities of daily living, particularly in a developing country such as India. Therefore, considering the needs of such patients, as well as the cost of joint replacement surgeries, salvaging the femoral head is of paramount importance, and several patients opt for femoral head salvage surgery.

The surgical treatment of femoral neck fracture remains controversial despite several advancements in the orthopedics domain. Nonunion and avascular necrosis are the two major complications of this fracture. Although the rate of nonunion has been reduced through anatomical reduction and stable fixation of fractures, the incidence of avascular necrosis is high [6]. In 1962, an autogenous muscle pedicle graft from the quadratus femoris muscle was used for the first time [7]. In addition, the application of fresh autogenous cancellous iliac bone chips along with muscle pedicle bone grafting has been reported to provide excellent outcomes [8]. However, whether muscle pedicle bone flap transplantation is effective in treating femoral neck fractures remains inconclusive.

It is very important to determine the effectiveness of muscle pedicle bone flap transplantation and its potential related factors. This not only builds a bridge between clinical and basic or translational science, but also for complex surgical problems, it is necessary for clinicians to understand the disease process, integrate new concepts into their surgical techniques, integrate new scientific discoveries, and improve the operation practice in the operating room $[9,10]$.

Therefore, this systematic review analyzed the available evidence on the efficacy and safety of muscle pedicle bone flap transplantation for femoral neck fractures in adults.

\section{Methods}

A systematic review was performed in accordance with the Cochrane Systematic Review Guidelines and the
Preferred Reporting Items for Systematic Reviews and Meta-Analyses checklist [11, 12]. This systematic review is based on the literature. All previously published studies were analyzed, and thus, ethical approval and patient consent were not required.

\section{Search strategy}

Databases including PubMed, EMBASE, IEEE, Web of Science, and Cochrane library were searched from their date of inception until March 2021 to identify studies that have assessed the efficacy of muscle pedicle bone flap transplantation in treating femoral neck fracture. No language restrictions were applied. The following search terms were used: "femoral neck fracture," "fracture of femoral neck," "muscle pedicle," "bone flap," and "bone grafting." In addition, the references of all the retrieved articles, including the relevant systematic reviews, were manually searched for additional relevant articles.

\section{Study selection criteria}

The inclusion and exclusion criteria for population, intervention, comparison, outcomes, and study were defined and applied.

\section{Participants}

Participants include adult patients diagnosed with femoral neck fractures, including displaced femoral neck fracture, ununited femoral neck fracture, and neglected femoral neck fracture. However, trials focusing on the treatment of patients with fracture not limited to femoral neck as well as reoperation were excluded.

\section{Intervention and comparison}

This review included studies on any type of muscle pedicle bone flap transplantation involving tensor fascia lata muscle, gluteus medius muscle, quadratus femoris muscle, and sartorius muscle pedicle bone grafting. However, studies that focused on bone grafting without muscle pedicle were excluded.

\section{Outcomes}

Primary outcomes were nonunion and avascular necrosis rates, whereas the secondary outcomes were the collapse rate, reoperation rate, and effective rate. Studies that did not report the eligible outcomes or data were excluded.

\section{Study}

Published or unpublished randomized controlled trials (RCTs) or non-RCTs were selected. In addition, case series were included. However, reviews or animal experiments were excluded.

The selection of studies was conducted independently by two reviewers. After removing duplicates, the 
reviewers screened the titles and abstracts of all the identified studies. Full text of all articles with potential relevance were retrieved for comprehensive assessment as per the inclusion criteria. Any disagreement was resolved through consensus with a third reviewer.

\section{Data collection and analysis}

All study characteristics and data, such as study population, sample size, and outcomes, were extracted as per the predefined criteria. Two authors independently extracted the data using a data extraction form. Any potential disagreement between the authors was resolved, and consensus was established through discussion involving a third author.

\section{Quality assessment}

In addition, two authors independently evaluated the methodological quality. The case series was assessed on the basis of the Institute of Health Economics quality appraisal checklist form [13]. This 20-criterion checklist has eight aspects, namely, study objective, study design, study population, intervention and co-intervention, outcome measures, statistical analysis, results, and conclusions, as well as competing interests and sources of support. Notably, criteria such as prospective study, consecutive recruitment, predefined inclusion or exclusion criteria, before and after outcome measurement, and sufficient follow-up data were used to examine how the study was executed, whereas other criteria (such as a clear statement of study objective, description of patient characteristics, interventions and co-interventions, reporting of adverse events, competing interests, and sources of support) focused on the reporting quality. The items were rated as follows: yes, unclear or partial, and no. Any discrepancies were resolved through discussion between all the authors.

\section{Statistical analysis}

Notably, both meta-analytical and level of evidence approaches were deemed inappropriate to formulate conclusions because of the inadequacy of comparison. The average nonunion, avascular necrosis, collapse, reoperation, and effective rates were calculated on the basis of the sum of the number of patients who experienced these events divided by the sum of the number of patients who received muscle pedicle bone flap transplantation.

\section{Results}

After the initial database search and removal of duplicates, provided a total of 147 potentially relevant articles, of which 45 duplicate publications were excluded. Of the remaining 102 articles, 42 were excluded after screening of the title and abstract. The remaining 60 articles, which included 40 studies with unapplicable disease or treatment, were excluded. Finally, 20 trials were included in the review $[8,14-32]$. Figure 1 illustrates the selection process of the studies.

\section{Study characteristics}

All the included studies were published between 1973 and 2020. Of the included studies, four were retrospective in nature; two, case-control studies; one, a nonrandomized control trial; and the remaining were case series. No RCT was included in this systematic review. Of the 20 publications, 3 were from the USA, 5 were from China, 1 was from Turkey, and the remaining were from India. The procedures used in these studies included quadratus femoris muscle pedicle bone grafting with screw fixation, open reduction and internal fixation, tensor fascia lata, and gluteus medius muscle pedicle bone grafting. Moreover, the included studies focused on patients with femoral neck fractures, mainly displaced fracture of the femoral neck, ununited femoral neck fractures, transcervical or subcapital fractures of the femoral neck, and neglected femoral neck fracture. Table 1 lists the characteristics of the studies included in the present meta-analysis.

\section{Quality assessment}

Table 2 presents the methodological quality of the studies. Losses to follow-up, adverse events, and the conclusions supported by the results were reported in all but one study [14]. The objective was not clearly stated in one study [30]. Except for four studies, all the studies were conducted prospectively $[18,21,27,31]$. Only three studies recruited consecutive patients [14, 23, 25]. Regarding intervention and co-intervention, except for two studies, all the studies clearly described the intervention of interest $[15,19]$. All studies except three $[15,19,32]$ had clearly described the additional interventions. Regarding the outcome measures, no study had reported the statistical tests used to appropriately assess the relevant outcomes, except for two, which provided estimates of random variability in the data analysis of relevant outcomes $[14,15]$. Overall, the methodological quality of the included studies was generally poor.

\section{Complications}

Among the included studies, 17 studies with 877 patients reported an average nonunion rate of $9.0 \%$ (95\% CI, 7.2-11.0\%). The average avascular necrosis rate of $6.7 \%$ was reported by 11 studies that enrolled $644 \mathrm{pa}-$ tients (95\% CI, 3.6-10.8\%).

The collapse rate was reported by 6 studies with 471 patients, and its $95 \% \mathrm{CI}$ ranged from 3.0 to $6.8 \%$ (average, $4.7 \%$ ). The reoperation rate was reported by eight studies that enrolled 546 patients, and its $95 \% \mathrm{CI}$ ranged 


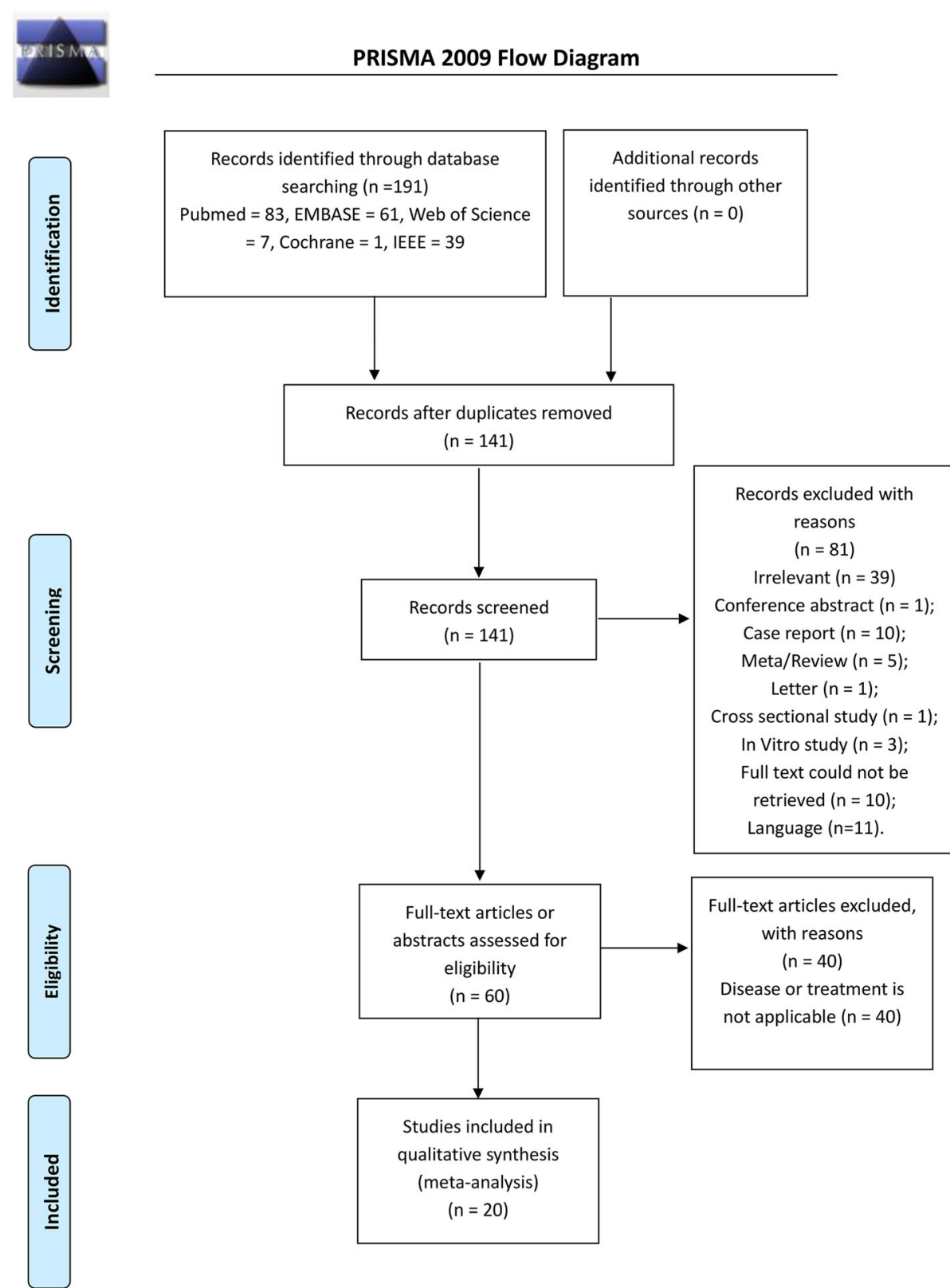

Fig. 1 Summary of the identification and selection process of relevant literature

from 2.9 to $13.4 \%$ (average, $7.3 \%$ ). The summary of complications is listed in Table 3.

\section{Effectiveness outcome}

The effective rate was reported by 10 studies involving 612 patients; of these, three used self-established criteria [27-29], four used the modified Harris hip score [16, 18, $21,25]$, one used the Salvati and Wilson score [20], one study used the Sanders score [22], and one study used the modified Postel and Merle d'Aubigne hip scoring to assess the effective rate [19]. An average effective rate of $73.4 \%$ were considered good, while rates of $15.4 \%$ and
$10.9 \%$ were considered fair and poor, respectively. Table 3 presents the summary of the efficacy outcome.

\section{Discussion}

\section{Summary of evidence}

We identified 20 studies that met our inclusion criteria. These studies included 1022 adult patients with femoral neck fractures who were treated with muscle pedicle bone flap transplantation. Notably, our systematic review indicated an average good effective rate of $73.4 \%$ for the muscle pedicle bone flap transplantation. Furthermore, the nonunion rate of muscle pedicle bone flap 


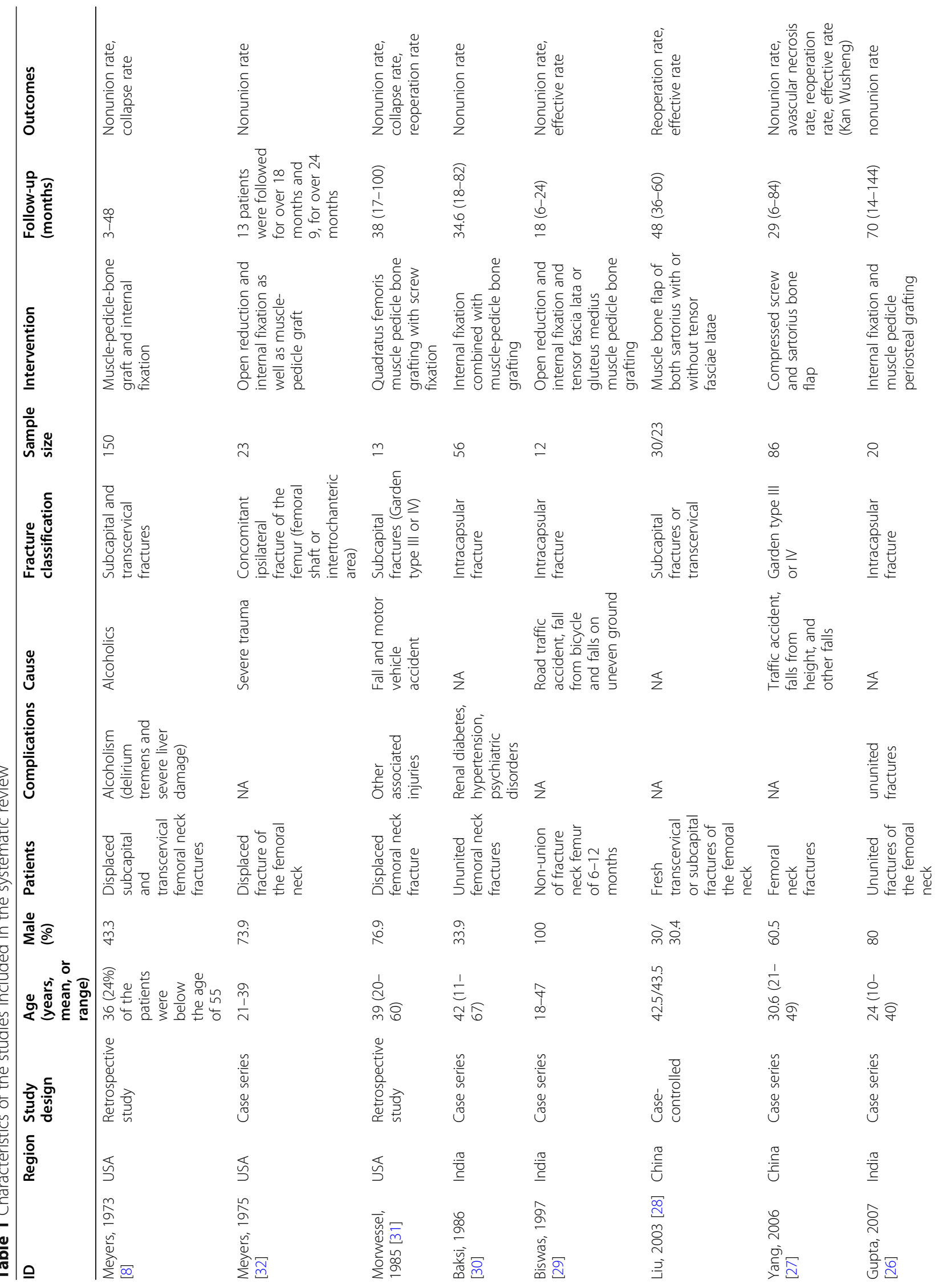




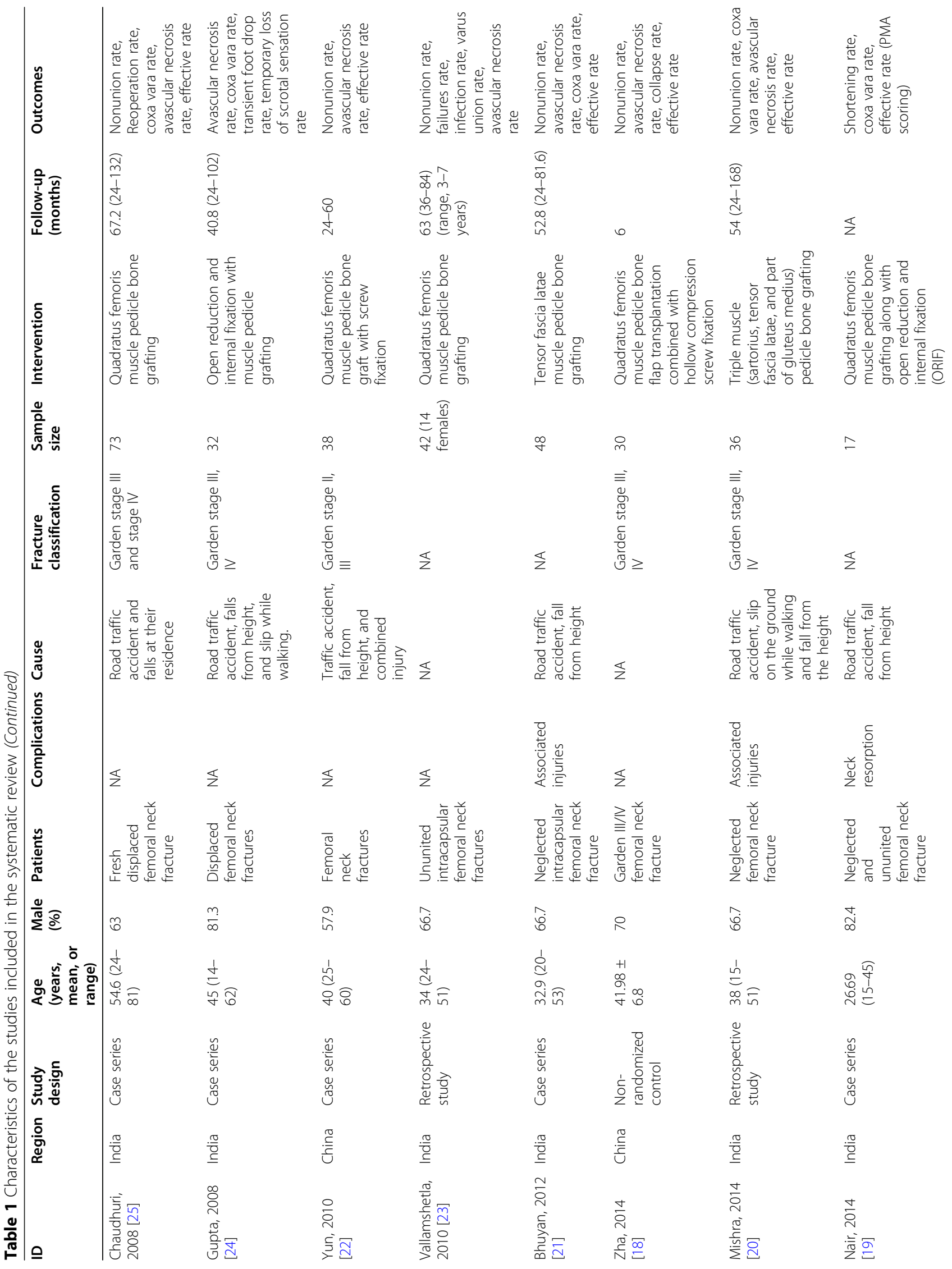




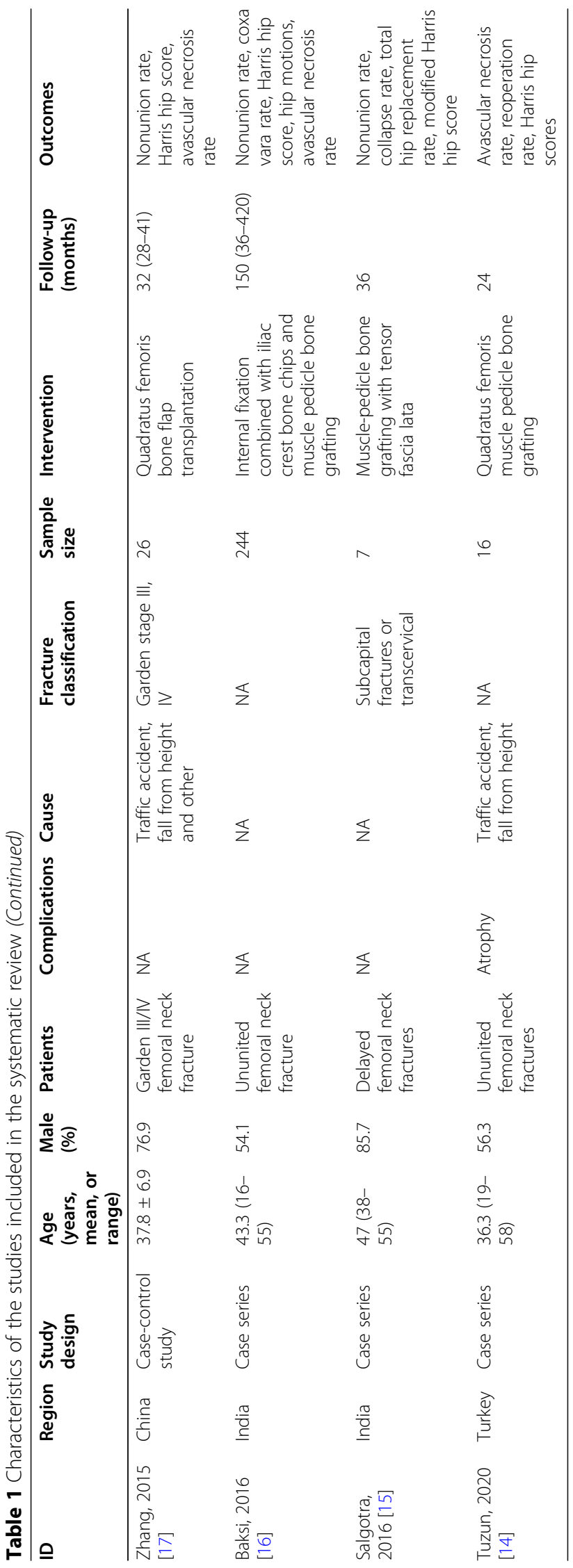




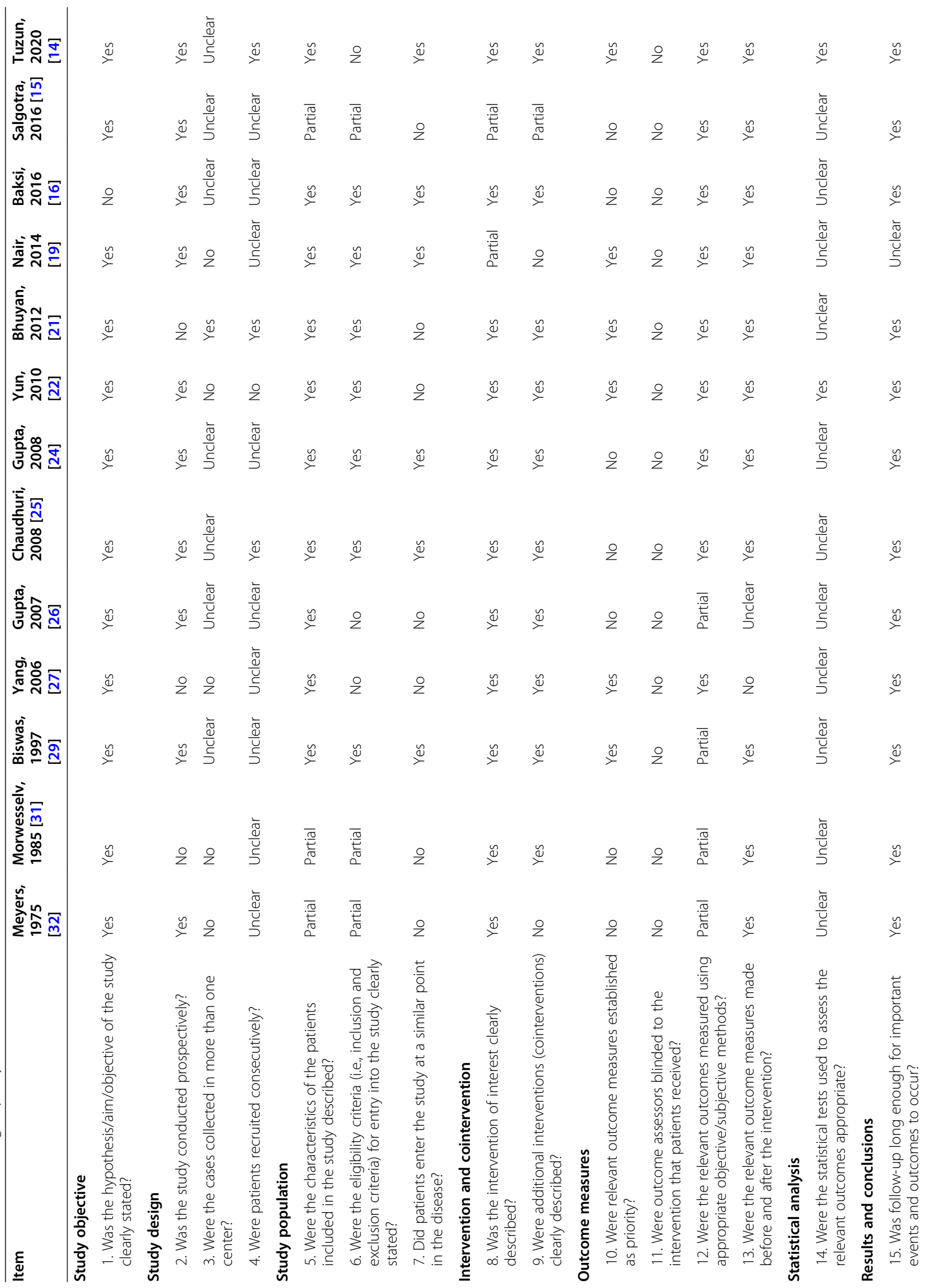




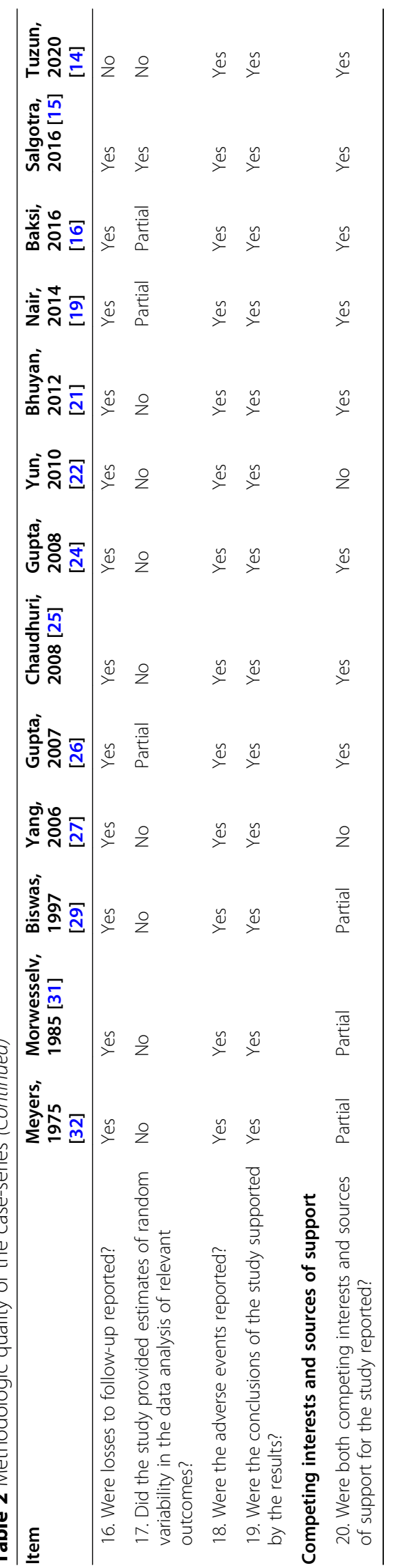


Table 3 Summary of complications and efficacy outcomes in the included studies

\begin{tabular}{lllll}
\hline & $\boldsymbol{N}$ & Rate $(\mathbf{9 5 \%} \mathrm{Cl})$ & $\boldsymbol{I}^{\mathbf{2}}$ & $\boldsymbol{P}$ (heterogeneity) \\
\hline Nonunion rate & 17 & $0.090(0.072,0.110)$ & 0 & 0.520 \\
Collapse rate & 6 & $0.047(0.030,0.068)$ & 30.73 & 0.205 \\
Effective rate & & & \\
$\quad$ Poor & 10 & $0.109(0.072,0.154)$ & 55.26 & 0.017 \\
$\quad$ Fair & 10 & $0.154(0.088,0.234)$ & 81.81 & $<0.001$ \\
$\quad$ Good & 10 & $0.734(0.626,0.830)$ & 86.33 & $<0.001$ \\
Reoperation rate & 8 & $0.073(0.029,0.134)$ & 78.67 & $<0.001$ \\
Avascular necrosis rate & 11 & $0.067(0.036,0.108)$ & 65.41 & 0.001 \\
Coxa vara rate & 6 & $0.101(0.051,0.166)$ & 67.95 & 0.008 \\
\hline
\end{tabular}

transplantation was $9.0 \%$, the avascular necrosis rate was $6.7 \%$, the collapse rate was $4.7 \%$, and the reoperation rate was $7.3 \%$.

One case series and literature review had summarized the evidence of muscle pedicle bone flap transplantation application in treating femoral neck fractures in adults [15]. However, the review included only six studies, and no quality assessment was conducted in the review. In that review, the muscle pedicle bone flap was compared with other treatments for delayed or ununited fractures of the femoral neck, and it claimed that the vascularized iliac crest, fibular, and periosteal grafting procedures are not popular procedures due to their time-consuming and technically demanding nature as well as due to the need for high competency from average orthopedic surgeons. Furthermore, despite the high union rate of such vascularized bone grafting series, these reviews were small and had short follow-up durations; therefore, it is challenging to predict the future occurrence of avascular necrosis in such patients. Conversely, the follow-up duration in the studies included in our systematic review was longer; the duration was approximately 3 years in 10 studies, and considerably longer in other studies (e.g., the average study duration in one study was 150 months), which is sufficiently long to predict the future occurrence of avascular necrosis rate in those patients.

\section{Nonunion and avascular necrosis rates of muscle pedicle bone flap transplantation}

Femoral head viability remains a major concern in femoral neck fractures. The two most challenging complications of femoral neck fractures in young adults are femoral head osteonecrosis and nonunion. Notably, osteonecrosis is a devastating complication in young patients due to the limited availability of options for young patients compared with that for elderly patients with the same condition afflicting the femoral head [5]. Despite advancements in surgical techniques, instrumentations, and imaging modalities, complications such as nonunion (10-30\%) and avascular necrosis (15-33\%) persist in affected patients [33, 34]. The average nonunion and avascular necrosis rates of muscle pedicle bone flap transplantation in our systematic review of 14 studies were less than $10 \%$. Moreover, bone grafting has evolved as a treatment modality for these fractures with predictable results in the long term. Furthermore, if used along with internal fixation in neglected femoral neck fracture, the vascularized bone grafting on a muscle pedicle, such as gluteus medius, quadratus femoris, or sartorius, further supplies blood to the femoral head by acting as a vascular inlay graft and structural bone graft to buttress the posterior femoral neck comminution and enhances stability, thereby improving osteosynthesis [35]. Nevertheless, risk factor analysis for nonunion and avascular necrosis rates was not performed in these studies; therefore, the systematic review could not provide suggestions to doctors regarding the nonunion and avascular necrosis rates.

Nonetheless, the muscle pedicle bone grafting approach is associated with the risk of extensive dissection and blood loss, particularly the risk of injuring the medial femoral circumflex artery. Commonly encountered problems with this approach are the need for experienced surgeons with excellent technical skills, long procedural duration, extensive soft tissue dissection, blood loss, and high risk of postoperative shock and infection [8]. Moreover, any torsion or tension in the muscle pedicle must be avoided when transferring the muscle pedicle bone graft to its recipient site [36]. The average duration of anesthesia and surgery in patients was 3.44 $\mathrm{h}$. Time variations could be attributed to differences in the skill and experience of the surgeon.

\section{Limitations of this review}

Our literature search was comprehensive without any language restrictions; however, we cannot rule out the availability of other small and unpublished trials. Moreover, the evidence in this review is limited because of the small sample sizes and low methodologic quality of the included studies. Notably, half of these studies had 
fewer than 20 patients, and the individual differences in rates were large. For example, Hou et al. reported a collapse rate of $0.00 \%$ in 5 patients, whereas Morwessel et al. reported a collapse rate of $23.08 \%$ in 13 patients $[29,34]$. Furthermore, most of the studies did not report the details pertaining to the diagnosis of the collapse and nonunion rates; thus, the consistency in these rates across the included studies could not be guaranteed. In addition, more than half of the studies (11 of 20) were from India, which may induce a risk of bias.

Moreover, there was no comparison of these case series, and thus, no meta-analysis could be conducted. Because most of the case series did not assess hip function by using functional parameters, such as the modified Harris hip score or Postel and Merle d'Aubigne's hip scoring, this review could not evaluate the functional recovery.

Based on the results of the present analysis of 20 articles, we found that the average effective rate of muscle pedicle bone flap transplantation was $73.4 \%$, with a nonunion rate of $9.0 \%$, avascular necrosis rate of $6.7 \%$, collapse rate of $4.7 \%$, and reoperation rate of $7.3 \%$. Our study has relatively low rates of nonunion and avascular necrosis, and if performed along with internal fixation and grafting of the vascularized bone on a muscle pedicle, it can provide further blood supply to the femoral head, enhance stability, and improve blood supply to the femoral head. However, risk factor analyses for nonunion and avascular necrosis rates were not performed in these studies; therefore, the systematic review could not provide suggestions to doctors regarding the nonunion and avascular necrosis rates.

\section{Conclusions}

Our systematic review of heterogenous studies with varying numbers of patients and varying surgical techniques indicated that muscle pedicle bone flap transplantation provides promising results with low rates of avascular necrosis and nonunion. Nonetheless, further research is needed to confirm the efficacy of muscle pedicle bone flap transplantation in treating fracture of the femoral neck.

\section{Abbreviations}

IHE: Institute of Health Economics; PICOS: Population, intervention, comparison, outcomes, and study; RCTs: Randomized controlled trials

\section{Acknowledgements}

Not applicable.

\section{Authors' contributions}

Yipeng Wu, Muguo Song, and Guangliang Peng conceived and coordinated the study; designed, performed, and analyzed the experiments; and wrote the paper. Yongqing Xu, Yang Li, Mingjie Wei, Hui Tang, Qian Lv, Teng Wang, and Xingbo Cai carried out the data collection and data analysis and revised the paper. All authors reviewed the results and approved the final version of the manuscript. The authors read and approved the final manuscript.

\section{Funding}

This study was funded by Yunnan Traumatology and Orthopaedics Clinical Medical Center (ZX20191001); and the MIF-based WNT/p38 MAPK/NF-KB Signaling Loop Regulates Osteogenesis, Osteoclastosis, and Coupling Under Inflammatory Conditions (81772367).

\section{Availability of data and materials}

The datasets used and/or analyzed during the current study are available from the corresponding author on reasonable request.

\section{Declarations}

Ethics approval and consent to participate

Not applicable.

\section{Consent for publication}

Not applicable.

\section{Competing interests}

The authors declare that they have no competing interests.

Received: 9 March 2021 Accepted: 26 April 2021

Published online: 08 May 2021

\section{References}

1. Force USPST, et al. Vitamin D, calcium, or combined supplementation for the primary prevention of fractures in community-dwelling adults: US Preventive Services Task Force Recommendation Statement. JAMA. 2018; 319(15):1592-9.

2. Force USPST, et al. Screening for osteoporosis to prevent fractures: US Preventive Services Task Force Recommendation Statement. JAMA. 2018; 319(24):2521-31.

3. Bray TJ, et al. The displaced femoral neck fracture. Internal fixation versus bipolar endoprosthesis. Results of a prospective, randomized comparison. Clin Orthop Relat Res. 1988:230:127-40.

4. Thillemann TM, Pedersen AB, Johnsen SP, Søballe K, Danish Hip Arthroplasty Registry. Implant survival after primary total hip arthroplasty due to childhood hip disorders: results from the Danish Hip Arthroplasty Registry. Acta Orthop. 2008;79(6):769-76. https://doi.org/10.1080/1745367081001683 0

5. Roshan A, Ram S. The neglected femoral neck fracture in young adults: review of a challenging problem. Clin Med Res. 2008;6(1):33-9. https://doi org/10.3121/cmr.2008.752.

6. Garden RS. Reduction and fixation of subcapital fractures of the femur. Orthop Clin North Am. 1974;5(4):683-712. https://doi.org/10.1016/500305898(20)31028-2.

7. Judet R. Treatment of fractures of the femur neck by pedicled graft. Acta Orthop Scand. 1962;32(1-4):421-7. https://doi.org/10.3109/174536762 08989601.

8. Meyers MH, Harvey JP Jr, Moore TM. Treatment of displaced subcapital and transcervical fractures of the femoral neck by muscle-pedicle-bone graft and internal fixation. A preliminary report on one hundred and fifty cases. The Journal of bone and joint surgery. Am Vol. 1973:55(2):257-74.

9. Mediouni M. A new generation of orthopaedic surgeons: "T-model". Current Orthopaedic Practice. 2019;30(5):444-5. https://doi.org/10.1097/BCO. 0000000000000786.

10. Mediouni M, R. Schlatterer D, Madry H, Cucchiarini M, Rai B. A review of translational medicine. The future paradigm: how can we connect the orthopedic dots better? Curr Med Res Opin. 2018;34(7):1217-29. https://doi. org/10.1080/03007995.2017.1385450.

11. Judet J. R. Judet, and J. Lefranc, [Fracture of the radial head in the child]. Ann Chir. 1962:16:1377-85.

12. Liberati A, Altman DG, Tetzlaff J, Mulrow C, Gotzsche PC, loannidis JPA, et al The PRISMA statement for reporting systematic reviews and meta-analyses of studies that evaluate healthcare interventions: explanation and elaboration. BMJ. 2009:339(jul21 1):b2700. https://doi.org/10.1136/bmj.b2700.

13. Guo B, Moga C, Harstall C, Schopflocher D. A principal component analysis is conducted for a case series quality appraisal checklist. J Clin Epidemiol. 2016;69:199-207 e2. https://doi.org/10.1016/j.jclinepi.2015.07.010. 
14. Tuzun, H.Y., et al., Results of quadratus femoris muscle pedicle bone grafting (Meyers' procedure) in the management of ununited femoral neck fractures. Hip International, 2020

15. Salgotra K, Kohli S, Vishwakarma N. Short-term results of muscle-pedicle bone grafting with tensor fascia lata for delayed femoral neck fractures; case series and literature review. Bull Emerg Trauma. 2016;4(2):101-4.

16. Baksi DD, Pal AK, Baksi DP. Osteosynthesis of ununited femoral neck fracture by internal fixation combined with iliac crest bone chips and muscle pedicle bone grafting. Indian J Orthop. 2016;50(4):366-73. https://doi.org/1 0.4103/0019-5413.185591.

17. Zhang XQ, Fan SC, Li HJ, Xie YH, Luo PG. Case-control study on the iliac bone flap transplantation with deep circumflex iliac artery and quadratus femoris bone flap transplantation for the treatment of Garden III/IV femoral neck fracture of young and middle-aged patients. Zhongguo Gu Shang. 2015;28(9):802-7.

18. Zha QL, et al. Quadratus femoris muscle pedicle bone flap transplantation combined with hollow compression screw fixation versus $\mathrm{AO}$ hollow compression screw fixation in the repair of femoral neck fracture in young and middle-aged patients. Chin J Tissue Eng Res. 2014;18(48):7792-6.

19. Nair N, Patro DK, Babu TA. Role of muscle pedicle bone graft as an adjunct to open reduction and internal fixation in the management of neglected and ununited femoral neck fracture in young adults: a prospective study of 17 cases. Eur J Orthop Surg Traumatol. 2014;24(7):1185-91. https://doi.org/1 0.1007/s00590-013-1384-x

20. Mishra PK, Gupta A, Gaur SC. Results of triple muscle (sartorius, tensor fascia latae and part of gluteus medius) pedicle bone grafting in neglected femoral neck fracture in physiologically active patients. Indian J Orthop. 2014;48(5):470-5. https://doi.org/10.4103/0019-5413.139856.

21. Bhuyan BK. Augmented osteosynthesis with tensor fascia latae muscle pedicle bone grafting in neglected femoral neck fracture. Indian J Orthop. 2012;46(4):439-46. https://doi.org/10.4103/0019-5413.97263.

22. Yun XD, Xia YY, Wan L, Wang J, Han H, Zhang CJ. Study on the long-term effects of the quadratus femoris muscle pedicle bone graft with screw fixation for the treatment of femoral neck fractures in young adults. Zhongguo Gu Shang. 2010;23(3):164-6.

23. Vallamshetla VRP, Sayana MK, Vutukuru R. Management of ununited intracapsular femoral neck fractures by using quadratus femoris muscle pedicle bone grafting in young patients. Acta Orthopaedica et Traumatologica Turcica. 2010;44(4):257-61. https://doi.org/10.3944/AOTT.201 0.2371.

24. Gupta AK, Rastogi S, Nath R. Internal fixation and muscle pedicle bone grafting in femoral neck fractures. Indian J Orthop. 2008;42(1):39-42. https:// doi.org/10.4103/0019-5413.38579.

25. Chaudhuri S. Closed reduction, internal fixation with quadratus femoris muscle pedicle bone grafting in displaced femoral neck fracture. Indian J Orthop. 2008;42(1):33-8. https://doi.org/10.4103/0019-5413.38578.

26. Gupta A. The management of ununited fractures of the femoral neck using internal fixation and muscle pedicle periosteal grafting. J Bone Joint Surg Br. 2007:89(11):1482-7.

27. Yang H, Guo Y, Nie W. Treatment of femoral neck fractures with compressed screw and sartorius bone flap in youth or middle age. Zhongguo Xiu Fu Chong Jian Wai Ke Za Zhi. 2006;20(11):1073-5.

28. Liu GP, Kang B, Zeng $H$, Tang YK, Tang XY, Xiong A, et al. Treatment of femoral neck fracture with muscle-bone flap of both tensor fasciae latae and sartorius. Chin J Traumatol. 2003;6(4):238-41.

29. Biswas SK, Salgotra KR, Lahree PK. Tensor fascia lata/gluteus medius muscle pedicle bone graft for non-union of femoral neck fractures. Med J Armed Forces India. 1997;53(1):19-23. https://doi.org/10.1016/S0377-1237(17)30638$X$.

30. Baksi DP. Internal fixation of ununited femoral neck fractures combined with muscle-pedicle bone grafting. J Bone Joint Surg Br. 1986;68(2):239-45.

31. Morwessel R, Evarts CM. The use of quadratus femoris muscle pedicle bone graft for the treatment of displaced femoral neck fractures. Orthopedics. 1985;8(8):972-6. https://doi.org/10.3928/0147-7447-19850801-06

32. Meyers MH, Moore TM, Harvey JP Jr. Displaced fracture of the femoral neck treated with a muscle-pedicle graft. With emphasis on the treatment of these fractures in young adults. J Bone Joint Surg Am. 1975;57(5):718-20. https://doi.org/10.2106/00004623-197557050-00034.

33. Wu CC, Shih CH, Chen WJ, Tai CL. Treatment of femoral neck nonunions with a sliding compression screw: comparison with and without subtrochanteric valgus osteotomy. J Trauma. 1999;46(2):312-7. https://doi. org/10.1097/00005373-199902000-00019.

34. Huang $\mathrm{CH}$. Treatment of neglected femoral neck fractures in young adults. Clin Orthop Relat Res. 1986;206:117-26.

35. Ly TV, Swiontkowski MF. Management of femoral neck fractures in young adults. Indian J Orthop. 2008;42(1):3-12. https://doi.org/10.4103/0019-5413.3 8574.

36. Hou SM, Hang YS, Liu TK. Ununited femoral neck fractures by open reduction and vascularized iliac bone graft. Clin Orthop Relat Res. 1993;294: 176-80. https://doi.org/10.1097/00003086-199309000-00023.

\section{Publisher's Note}

Springer Nature remains neutral with regard to jurisdictional claims in published maps and institutional affiliations.
Ready to submit your research? Choose BMC and benefit from:

- fast, convenient online submission

- thorough peer review by experienced researchers in your field

- rapid publication on acceptance

- support for research data, including large and complex data types

- gold Open Access which fosters wider collaboration and increased citations

- maximum visibility for your research: over $100 \mathrm{M}$ website views per year

At BMC, research is always in progress.

Learn more biomedcentral.com/submissions 